\title{
Muscle sympathetic nerve activity and hemodynamic alterations in middle-aged obese women
}

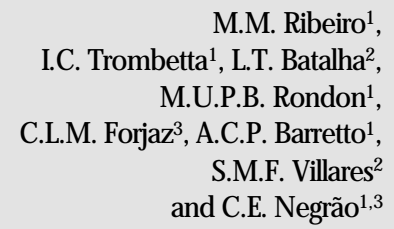

\section{Correspondence}

C.E. Negrão

Unidade de Reabilitação

Cardiovascular e Fisiologia

do Exercício, InCor

Av. Enéas C. Aguiar, 44, andar AB

05403-000 São Paulo, SP

Brasil

Fax: + 55-11-3069-5043

E-mail: cndnegrao@incor.usp.br

Research supported by FAPESP (No. 1998/15983-8).

Received July 13, 2000

Accepted December 12, 2000

\author{
${ }^{1}$ Instituto do Coração, ${ }^{2}$ Departamento de Endocrinologia,

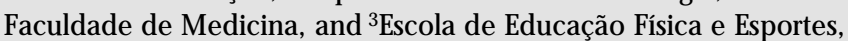 \\ Universidade de São Paulo, São Paulo, SP, Brasil
}

\section{Abstract}

To study the relationship between the sympathetic nerve activity and hemodynamic alterations in obesity, we simultaneously measured muscle sympathetic nerve activity (MSNA), blood pressure, and forearm blood flow (FBF) in obese and lean individuals. Fifteen normotensive obese women $\left(\mathrm{BMI}=32.5 \pm 0.5 \mathrm{~kg} / \mathrm{m}^{2}\right)$ and 11 agematched normotensive lean women $\left(\mathrm{BMI}=22.7 \pm 1.0 \mathrm{~kg} / \mathrm{m}^{2}\right)$ were studied. MSNA was evaluated directly from the peroneal nerve by microneurography, FBF was measured by venous occlusion plethysmography, and blood pressure was measured noninvasively by an autonomic blood pressure cuff. MSNA was significantly increased in obese women when compared with lean control women. Forearm vascular resistance and blood pressure were significantly higher in obese women than in lean women. FBF was significantly lower in obese women. BMI was directly and significantly correlated with MSNA, blood pressure, and forearm vascular resistance levels, but inversely and significantly correlated with FBF levels. Obesity increases sympathetic nerve activity and muscle vascular resistance, and reduces muscle blood flow. These alterations, taken together, may explain the higher blood pressure levels in obese women when compared with lean age-matched women.

Obesity is associated with hypertension, diabetes and dyslipidemia, and, in consequence, cardiovascular disease (1-4). In obese individuals, the hyperinsulinemia provoked by insulin resistance increases sympathetic nerve activity, which seems to link obesity to high blood pressure. Interesting, however, is the fact that not all obese individuals are hypertensive. The hypertensive effect of obesity is lower in Pima Indians, Hispanic Ameri- cans and African Americans than it is in Whites $(5,6)$. Besides, even among Whites, not all obese individuals are hypertensive. Therefore, it is likely that the levels of blood pressure may be related to the etiology of obesity and/or the genetic mechanisms of obesity $(7,8)$.

It has been described that obese individuals have vascular dysfunction. The peripheral blood flow (9) and the vasodilatory re-

\section{Key words}

- Sympathetic nerve activity

Blood pressure

- O besity 
sponse during mental stress are reduced in obese individuals (10). The mechanisms underlying these hemodynamic responses are unclear, but may be related to insulin resistance and/or endothelial dysfunction. Alternatively, to our understanding, there is a possibility that the increased sympathetic nerve activity also plays a role in the reduced peripheral blood flow in obese individuals.

In an attempt to obtain more insights into the potential functional consequences of increased sympathetic nerve activity in obesity, we simultaneously measured muscle sympathetic nerve activity, blood pressure, and forearm blood flow in obese and lean individuals.

After written informed consent was obtained, a total of 15 normotensive obese women (age $34 \pm 1.4$ years, BMI $32.5 \pm 0.5$ $\mathrm{kg} / \mathrm{m}^{2}$ ), admitted to the Clinical Endocrinology Center for Women of the General Clinical Hospital, University of São Paulo, and 11 age-matched normotensive lean women (age $36 \pm 2.6$ years, BMI $22.7 \pm 1.0 \mathrm{~kg} / \mathrm{m}^{2}$ ) participated in this study. The individuals were classified as normotensive according to the criteria of the Joint National Committee on Prevention, Detection, Evaluation, and Treatment of High Blood Pressure (11).

All individuals had normal glucose tolerance and none were taking any medication or had any evidence of metabolic or cardiovascular disease at the time of the study. The study protocol was approved by the Human Subject Protection Committees of the Heart Institute and Clinical Hospital, School of Medicine, University of São Paulo. Obese and lean women abstained from caffeine for $24 \mathrm{~h}$ before the study, which was conducted in the postabsorptive state.

Muscle sympathetic nerve activity was directly measured from the peroneal nerve by microneurography (12). Multiunit postganglionic muscle sympathetic nerve recordings were obtained using a tungsten microelectrode (5 to $15 \mu \mathrm{m}$ tip diameter). The signals were amplified by a factor of 50,000 to 100,000 and bandpass filtered (700 to $2000 \mathrm{~Hz}$ ). For the recordings, muscle sympathetic nerve activity was determined as the integrated average (in $\mu$ volts) of the signal amplitude, $U(t)$, over a period of 0.1 s, i.e., as ${ }_{t}^{t+1} U(t) d t / 0.1$ s. For analysis, muscle sympathetic nerve activity was evaluated by number of bursts per minute. Forearm blood flow was measured by venous occlusion plethysmography with the arm elevated above the heart level. A mercury-filled silastic tube attached to a low-pressure transducer was placed around the forearm and connected to a plethysmograph (Hokanson, Bellevue, WA, USA). Sphygmomanometer cuffs were placed around the wrist and upper arm. At 15-s intervals, the upper cuff was inflated above venous pressure for 7 to $8 \mathrm{~s}$. Forearm blood flow $\left(\mathrm{ml} \mathrm{min}{ }^{-1} 100 \mathrm{ml}\right.$ tissue $\left.{ }^{-1}\right)$ was determined on the basis of a minimum of four separate readings. Forearm vascular resistance (units) was calculated by dividing mean arterial pressure by forearm blood flow. Blood pressure was monitored noninvasively with a finger arterial blood pressure monitor (FINAPRES, Ohmeda, Englewood, CO, USA). Heart rate was monitored continuously through lead II of the ECG.

Baseline data of muscle sympathetic nerve activity, forearm blood flow, mean blood pressure, forearm vascular resistance, and heart rate for obese and lean women were compared by the unpaired Student $t$-test. The Pearson correlation coefficient was used to evaluate the correlation between variables, with the level of significance set at $\mathrm{P}<0.05$. Data concerning muscle sympathetic nerve activity, forearm blood flow, mean blood pressure, forearm vascular resistance, and heart rate are presented as mean $\pm \mathrm{SEM}$.

Baseline measurements of muscle sympathetic nerve activity, forearm vascular resistance, forearm blood flow, blood pressure and heart rate are shown in Table 1. Muscle sympathetic nerve activity was significantly increased in obese women when compared with lean women. Forearm vascular resis- 
tance was significantly higher and forearm blood flow was significantly lower in obese women than in lean women. Although obese women were normotensive, their systolic, mean and diastolic blood pressure levels were significantly higher than those of agematched normotensive lean women. Heart rate was similar for the two groups studied.

Further analysis showed that body mass index was directly and significantly correlated with muscle sympathetic nerve activity (Figure 1A), mean blood pressure (Figure 1B), and forearm vascular resistance (Figure 1C), but inversely and significantly correlated with forearm blood flow (Figure 1D). In addition, muscle sympathetic nerve activity showed a strong tendency toward a direct correlation with forearm vascular resistance $(\mathrm{r}=0.35, \mathrm{P}<0.09)$.

The main finding of the present study is that obesity increases muscle sympathetic nerve activity in women. Besides, this increase in sympathetic nerve activity seems to have hemodynamic implications because obese women have higher muscle vascular resistance and blood pressure levels and lower muscle blood flow than lean agematched women.

We used direct intraneural recordings to measure sympathetic nerve activity, an approach that allowed us to evaluate the tonic control of peripheral sympathetic nerve activity in both obese and lean women. The increase in sympathetic nerve activity in obese women has also been reported for other groups of obese individuals (13-15). This alteration in sympathetic nerve activity has been explained by the increase in insulin resistance/hyperinsulinemia or, alternatively, baroreflex dysfunction (16-18). The acute elevation of plasma insulin levels in humans provokes an increase in sympathetic nerve activity as evaluated by plasma norepinephrine or, more recently, by direct microneurography recordings. Reduction in body weight by a low-calorie diet seems to restore baroreflex control of heart rate and muscle sympathetic nerve activity in obese individuals (19). More recently, however, it has been elegantly demonstrated that obstructive sleep apnea plays a role in the augmented sympathetic nerve activity in obesity. Because this factor was not controlled in the present study, the increased sympathetic nerve activity in the obese individuals may be explained in part by the obstructive

Table 1 - Baseline measurements of muscle sympathetic nerve activity (MSNA), forearm vascular resistance (FVR), forearm blood flow (FBF), systolic (SBP), diastolic (DBP) and mean blood pressures (MBP), and heart rate (HR) in obese and lean women.

Data are reported as means $\pm \mathrm{SEM}$. $\mathrm{P}=$ Statistical difference between groups (unpaired Student t-test).

\begin{tabular}{lrrl}
\hline & \multicolumn{1}{c}{ Lean } & Obese & $P$ \\
\hline MSNA (bursts/min) & $27 \pm 1.5$ & $35 \pm 1.8$ & 0.002 \\
FVR (units) & $41 \pm 3.0$ & $57 \pm 4.0$ & 0.006 \\
FBF (ml min-1 $\left.100 \mathrm{ml}^{-1}\right)$ & $2.1 \pm 0.1$ & $1.7 \pm 0.1$ & 0.04 \\
SBP (mmHg) & $121 \pm 3.6$ & $137 \pm 2.6$ & 0.001 \\
DBP (mmHg) & $64 \pm 2.7$ & $74 \pm 2.6$ & 0.01 \\
MBP (mmHg) & $83 \pm 2.4$ & $94 \pm 2.3$ & 0.004 \\
HR (beats/min) & $67 \pm 2.4$ & $70 \pm 1.8$ & 0.2
\end{tabular}

A

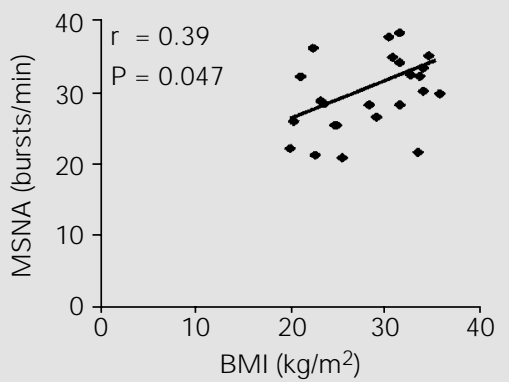

C

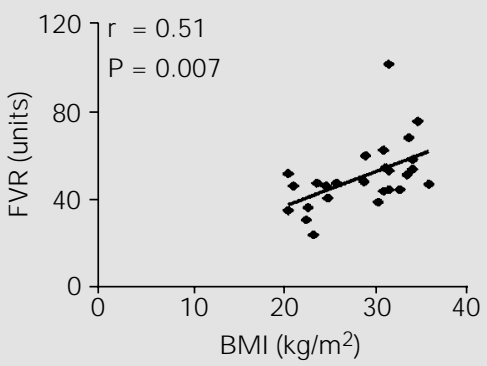

B

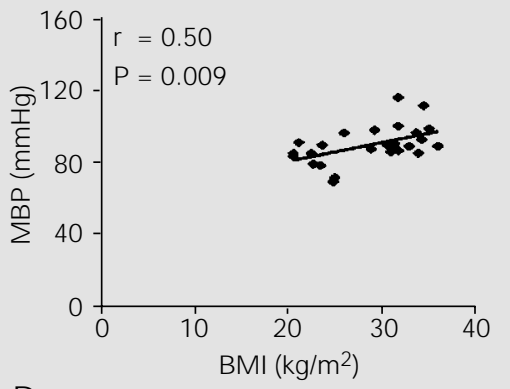

D

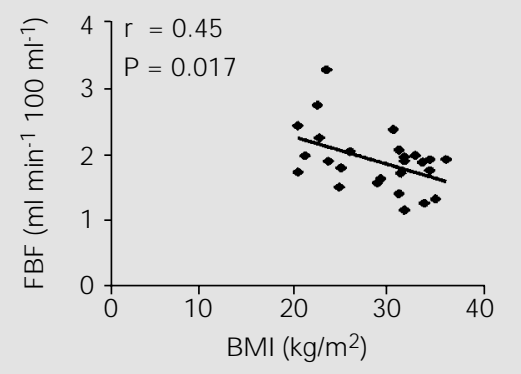

Figure 1 - Correlation between body mass index (BMI) and muscle sympathetic nerve activity (MSNA, panel A), mean blood pressure (MBP, panel $B$ ), forearm vascular resistance (FVR, panel C), and forearm blood flow (FBF, panel D) in middle-aged obese women. The Pearson correlation coefficient was used to evaluate the correlation between variables. 
sleep apnea.

In the present study, the tendency toward a significant correlation between muscle sympathetic nerve activity and forearm vascular resistance may represent one of the factors contributing to the higher blood pressure levels found in obese women when compared with age-matched lean women. In addition, the increased muscle sympathetic nerve activity may explain the lower forearm blood flow (9) and the reduced vasodilatory response during mental stress in obese individuals (10).

These autonomic and hemodynamic alterations in obesity have clinical implications. They increase the possibility of ad- verse cardiac events in obese individuals, especially during conditions in which the cardiovascular system requires increased functioning, such as defense reaction or exercise.

In conclusion, although obesity is not always associated with hypertension, obesity increases sympathetic nerve activity and muscle vascular resistance, and reduces muscle blood flow in middle-aged women. These alterations may act in concert to increase blood pressure levels in middle-aged obese women. Although these blood pressure levels are within normal limits, they are significantly higher in middle-aged obese women than in middle-aged lean women.

\section{References}

1. Hubert HB, Feinleib M, McNamara PM \& Castelli WP (1983). Obesity as an independent risk factor for cardiovascular disease: A 26-year follow-up of participants in the Framingham Heart Study. Circulation, 67: 968-977.

2. Manson JE, Colditz GA, Stampfer MJ, Willett WC, Rosner B, Monson RR, Speizer FE \& Hennekens CH (1990). A prospective study of obesity and risk of coronary heart disease in women. New England J ournal of Medicine, 322: 882889.

3. Mark AL, Correia M, Morgan DA, Shaffer RA \& Haynes WG (1999). Obesity-induced hypertension. New concepts from the emerging biology of obesity. Hypertension, 33 (Part II): 537-541.

4. Scherrer U \& Sartori C (1997). Insulin as a vascular and sympathoexcitatory hormone. Implication for blood pressure regulation, insulin sensitivity and cardiovascular morbidity. Circulation, 96: 41044113.

5. Hsueh WA \& Buchanan TA (1994). Obesity and hypertension. Endocrinology and Metabolism Clinics of North America, 23: 405-427.

6. Van Itallie TB (1985). Health implications of overweight and obesity in the United States. Annals of Internal Medicine, 103: 983-988.

7. Meirhaeghe $A$, Helbecque $N$, Dominique C \& Amouyel P (1999). ß-Adrenoceptor gene polymorphism, body weight, and physical activity. Lancet, 353: 896.

8. Large V, Hellstrom L, Reynisdottir S, Lonnqvist $F$, Eriksson $P$, Lannfelt $L$ \& Arner P (1997). Human beta-2 adrenoceptor gene polymorphisms are highly frequent in obesity and associate with altered adipocyte beta-2 adrenoceptor function. J ournal of Clinical Investigation, 100: 3005-3013.

9. Vollenweider $P$, Randin D, Tappy L, J equier E, Nicod P \& Scherrer U (1994). Impaired insulin-induced sympathetic neural activation and vasodilatation in skeletal muscle in obese humans. J ournal of Clinical Investigation, 93: 2365-2371.

10. Rockstroh J K, Schmieder RE, Schachinger H \& Messerli FH (1992). Stress response pattern in obesity and systemic hypertension. American J ournal of Cardiology, 70: 1035-1039.

11. The Sixth Report of the J oint National Committee on Prevention, Detection, Evaluation, and Treatment of High Blood Pressure (1997). Archives of Internal Medicine, 157: 2413-2446.

12. Middlekauff $H R$, Nguyen $A H$, Negrão $C E$, Nitzsche EU, Hoh CK, Natterson BA, Hamilton MA, Fonarow GC, Hage A \& Moriguchi JD (1997). Impact of acute mental stress on sympathetic nerve activity and regional blood flow in advanced heart failure. Circulation, 96: 1835-1842.

13. Scherrer U, Owlya R \& Lepori M (1996).
Body fat and sympathetic nerve activity. Cardiovascular Drugs and Therapy, 10: 215-222.

14. Peterson HR, Rothschild $M$, Weinberg CR, Fell RD, McLeish KR \& Pfeifer MA (1988). Body fat and the activity of the autonomic nervous system. New England J ournal of Medicine, 318: 1077-1083.

15. Scherrer U, Randin D, Tappy L, Vollenweider P, Jéquier E \& Nicod $P$ (1994). Body fat and sympathetic nerve activity in healthy subjects. Circulation, 89: 26342640.

16. Grassi G, Seravalle G, Cattaneo BM, Giovanni BB, Lanfranchi A, Colombo M, Giannattasio C, Brunani A, Cavagnini $F$ \& Mancia G (1995). Sympathetic activation in obese normotensive subjects. Hypertension, 25 (Part 1): 560-563.

17. Wehberg KE, West DB, Kieswetter $C$ \& Granger J P (1990). Baroreflex sensitivity in the canine model of obesity-induced hypertension. American J ournal of Physiology, 259 (Part 2): R981-R985.

18. Laederach-Hofmann K, Mussgay L \& Ruddel H (2000). Autonomic cardiovascular regulation in obesity. J oumal of Endocrinology, 164: 59-66.

19. Grassi G, Seravalle G, Colombo M, Bolla G, Cattaneo BM, Cavagnini F \& Mancia G (1998). Body weight reduction, sympathetic nerve traffic, and arterial baroreflex in obese normotensive humans. Circulation, 97: 2037-2042. 